\title{
Efecto del Nivel de Grasa y Velocidad de Agitación en la Hidrolisis Enzimática de Vísceras de Tilapia Roja (Orechromis sp.)
}

\author{
Leidy J. Gómez y José E. Zapata \\ Grupo de Nutrición y Tecnología de Alimentos, Facultad de Ciencias Farmacéuticas y Alimentarias, \\ Universidad de Antioquia UdeA, Calle 67 No. 53 - 108, Medellín, Colombia. \\ (e-mail: ljohanna.gomez@udea.edu.co,jedgar_4@yahoo.es)
}

Recibido Dic. 19, 2016; Aceptado Feb. 22, 2017; Versión final Mar. 19, 2017, Publicado Ago. 2017

\section{Resumen}

Se evaluó el efecto de la concentración de grasa en las vísceras $(\mathrm{Cg})$ y la velocidad de agitación (Va), sobre el grado el hidrólisis $(\mathrm{GH})$ en el proceso de hidrolisis enzimática de proteínas de vísceras de tilapia roja (Orechromis sp.) con Alcalasa 2,4L. Esto se realizó mediante un diseño experimental de superficie de respuestas central compuesto. Se evaluó además el mecanismo de inhibición de la grasa presente en las vísceras sobre Alcalasa 2,4L y la posible inactivación de la enzima por daño mecánico con la agitación. Los datos se ajustaron a un modelo polinomial de segundo orden con un $\mathrm{R}^{2}$ de 0,84 . Se observó que $\mathrm{Cg}$ muestra un efecto lineal negativo sobre el $\mathrm{GH}$, mientras que Va muestra un efecto parabólico. Los resultados sugieren también, que la Alcalasa $2,4 \mathrm{~L}$ no presenta inactivación por esfuerzo de cillaza en las primeras cuatro horas del proceso, pero si presenta una inhibición competitiva por efecto de la grasa.

\section{Effect of Fat Level and Stirring Speed on the Enzymatic Hydrolysis of Red Tilapia Viscera (Orechromis sp.)}

\begin{abstract}
The effects of viscera fat concentration $(\mathrm{Cg})$ and stirring speed $(\mathrm{Va})$ on the hydrolysis degree $(\mathrm{GH})$ in the process of enzymatic hydrolysis of red tilapia (Orechromis $s p$.) viscera protein with Alcalase 2,4L were evaluated. This was done through a central composite design and response surface methodology. Additionally, the inhibition mechanism of fat in the viscera on Alcalase 2,4L and the possible inactivation of the enzyme by mechanical damage by agitation were also evaluated. The experimental data were fitted using a second order polynomial model with an $\mathrm{R}^{2}$ of 0,84 . It was observed that $\mathrm{Cg}$ shows a negative linear effect on $\mathrm{GH}$, while Va shows a parabolic effect. The results also suggest, that there is not Alcalase 2,4L inactivation by shear stress in the first four hours of the process, but it presents a competitive inhibition effect by fat.
\end{abstract}

Keywords: enzymatic hydrolysis; vísceras; Oreochromis sp.; Alcalase 2.4L; enzyme inhibition 


\section{INTRODUCCIÓN}

La industria piscícola producen más del $60 \%$ de subproductos, los cuales comprenden restos de fileteo (15$20 \%)$, piel y aletas (1-3\%), huesos (9-15\%), cabezas (9-12\%), vísceras (12-18\%) y escamas (5\%) (Martínez et al., 2015). El alto contenido en proteína y lípidos de estos subproductos y su inadecuado vertimiento, los convierte en sustancias con impactos ambientales negativos dada la alta demanda bioquímica de oxígeno (García et al., 2009), pero al mismo tiempo son fuentes de proteínas y lípidos con importante potencial de revalorización (Chalamaiah et al., 2012). Recientemente se han generado investigaciones para el aprovechamiento de la proteína presente en las vísceras de pescado, las cuales han logrado obtener péptidos con importantes propiedades bioactivas y tecno-funcionales (Je et al., 2015; Saidi et al., 2014). Estos péptidos pueden ser generados desde la proteína precursora de múltiples maneras, pero una de las más utilizadas es la hidrólisis enzimática por medio de proteasas (Gómez y Zapata, 2014; Gomez y Zapata, 2016; Je et al., 2015; Robert et al., 2015; Zhu et al., 2015). Las proteasas son enzimas que catalizan la hidrólisis de los enlaces peptídicos de las proteínas con diferentes grados de intensidad y de selectividad (Copeland, 2000), lográndose obtener péptidos con diferentes propiedades como quelantes de Zinc (Zhu et al., 2015), antimicrobianos (Robert et al., 2015), antioxidantes (Gomez y Zapata, 2016; Je et al., 2015) y antihipertensivos (Gómez y Zapata, 2014), entre otros. Diferentes reportes de literatura han establecido la relación existente entre la actividad biológica de los péptidos y su peso molecular (Gomez y Zapata, 2016; Saidi et al., 2014; Zhu et al., 2015). En particular, las fracciones de péptidos con pesos moleculares entre 1 4kDa, serían los de mayor interés para usos nutricionales y/o farmacéuticos (Robert et al., 2015; Saidi et al., 2014). Por lo tanto, obtener hidrolizados con altos grados de hidrólisis (GH), incrementa la posibilidad de obtener péptidos bioactivos (Gómez et al., 2013; Gómez y Zapata, 2014). Por otro lado es de importancia evitar las variaciones en actividad que puede sufrir la enzima durante la reacción hidrolítica, las cuales pueden ocurrir por desnaturalización, agregación o inactivación enzimática, que se producen por factores tales como temperatura (Valencia et al., 2014; Verhaeghe et al., 2016), pH (England et al., 2014), esfuerzo de cizalla (Caussette et al., 1997; Colombié et al., 2001) o sustancias que interfieren en la catálisis (Šližyte et al., 2005; Zheng et al., 2015).

Algunas variables como el $\mathrm{pH}$ y la temperatura, han sido ampliamente estudiadas en hidrolisis de proteínas con diferentes enzimas y sustratos (Lassé et al., 2015; Valencia et al., 2014; Verhaeghe et al., 2016), específicamente en la hidrólisis de vísceras de tilapia se concluyó que las mejores condiciones de operación son $\mathrm{pH} 9.5$ y temperatura de $53^{\circ} \mathrm{C}$ usando Alcalasa $2,4 \mathrm{~L}$, enzima que demostró una mayor eficiencia en la catálisis de la reacción en comparación con otras proteasas (Baez et al., 2016). Sin embargo factores como el efecto de la agitación y la presencia de sustancias inhibidoras en la muestra han sido poco estudiados. En este sentido algunos autores han reportado la influencia de la agitación mecánica en la estabilidad enzimática (Caussette et al., 1997; Colombié et al., 2001); pero en cuanto a daños mecánicos sufridos por enzimas proteolíticas por efecto de la agitación en procesos de hidrolisis de proteínas, no existen aún reportes que permitan identificar la importancia de esta variable. Por otro lado, aunque vísceras de diferentes géneros de peces han sido usadas para la obtención de hidrolizados, no se han realizado estudios que permitan identificar si algunos de los componentes mayoritarios, como es el caso de la grasa, presenta efectos inhibitorios sobre la actividad de la enzima. Este trabajo busca determinar el efecto que tiene la velocidad de agitación y el contenido de grasa de las vísceras sobre el grado de hidrólisis $(\mathrm{GH})$, en la hidrolisis enzimática de vísceras de tilapia roja (VTR), utilizando la proteasa alcalina Alcalasa 2,4L.

\section{MATERIALES Y MÉTODOS}

Se describe la metodología en sus varios aspectos: manejo del sustrato, análisis proximal, hidrólisis enzimática, el diseño experimental, la determinación de la actividad enzimática, el estudio de la agitación sobre la actividad de la Alcalasa 2,4l, la determinación del patrón de inhibición de la grasa sobre la Alcalasa 2,4l y finalmente el análisis estadístico.

\section{Manejo del sustrato}

Las VTR se obtuvieron en cadena de frío de la Piscícola el Gaitero (Antioquia), tomando muestras de lotes de producción diferentes. Las vísceras fueron homogenizadas en un procesador de alimentos (Quick ' $n$ Easy, Black\&Decker, USA), calentadas a $90{ }^{\circ} \mathrm{C}$ por 20 minutos para inactivar las enzimas endógenas y favorecer la separación de la grasa. Posteriormente se redujo la temperatura gradualmente de la siguiente forma: $25^{\circ} \mathrm{C}$ por $20 \mathrm{~min}, 4^{\circ} \mathrm{C}$ por $40 \mathrm{~min}$ y $-20^{\circ} \mathrm{C}$ durante $24 \mathrm{~h}$. Pasadas las $24 \mathrm{~h}$, la grasa fue separada de la fracción acuosa y almacenadas separadamente a $-20{ }^{\circ} \mathrm{C}$ hasta el momento de la hidrólisis, en la cual se utilizó Alcalasa 2,4 L grado alimenticio (Novo Nordisk Co., Dinamarca).

\section{Análisis proximal}

El contenido de humedad, grasa, proteína y cenizas de las VTR, fueron analizados de acuerdo a los métodos de la AOAC (AOAC, 2005). Los resultados fueron expresados en base húmeda. 


\section{Hidrólisis Enzimática}

Las hidrólisis se llevaron a cabo en un reactor de vidrio con $500 \mathrm{~mL}$ de solución de trabajo, con concentraciones de sustrato de $4 \mathrm{~g}$ proteína/L, relación enzima/sustrato $(\mathrm{E} / \mathrm{S})$ de $10 \%(\mathrm{p} / \mathrm{p}), \mathrm{pH} 9,5 \mathrm{y}$ temperatura de $53^{\circ} \mathrm{C}$, con base en resultados previos (Baez et al., 2016). El control de pH y temperatura se hizo con un electrodo combinado de vidrio, conectado a un Titulador automático Titrando 842 (Metrohm, Suiza) operado por un ordenador (software Tiamo 1.2.1, Metrohm, Suiza). La velocidad de agitación del sistema de reacción ( $\mathrm{Va}$ ) y la concentración de grasa en las vísceras $(\mathrm{Cg})$, se varió según lo define el diseño experimental (Tabla 1). Para llevar las muestras al valor de $\mathrm{Cg}$ deseado, se pesó la cantidad de grasa necesaria según el balance de masas y se mezcló con las vísceras y el agua adicionada, agitando la mezcla a $720 \mathrm{rpm}$ a una temperatura de $53^{\circ} \mathrm{C}$ durante $10 \mathrm{~min}$, previo a la reacción de hidrólisis. La reacción fue monitoreada durante $4 \mathrm{~h}$ por medio del $\mathrm{GH}$, expresado como la relación entre el número de enlaces peptídicos hidrolizados $(h)$ y el número de enlaces peptídicos totales en la proteína nativa por unidad de peso (ht) (Adler-Nissen, 1986). El método empleado para la determinación del GH fue el de valoración del protón o método del pH-estático. El cual consiste en mantener constante el pH del medio de reacción con adición de una solución básica $(\mathrm{NaOH})$, dado que a medida que la hidrólisis avanza en medio alcalino, el grupo carboxilo terminal se disocia por completo y los protones formados se reparten de acuerdo con el equilibrio de protonación de los grupos $\alpha$-amino liberados. La base agregada para mantener constante el pH neutraliza únicamente los protones que son sustituidos por el catión de la base (Guadix et al., 2000). El cálculo del GH se hizo según la ecuación 1 (Adler-Nissen, 1986).

$D H(\%)=\frac{\mathrm{B} \mathrm{N} \mathrm{N}_{\mathrm{B}}}{\mathrm{M}_{\mathrm{p}} \alpha \mathrm{h}_{\mathrm{t}}} \times 100$

Donde $B$ es el volumen consumido de base en $L, M_{P}$ es la masa de la proteína en $\mathrm{kg}, \mathrm{N}_{\mathrm{B}}$ es la normalidad de la base y a es el grado de disociación de los grupos aminos liberados en la reacción. Se empleó un $h_{t}$ de $8,6 \mathrm{Eqv} / \mathrm{Kg}$ que ha sido reportado para proteínas del pescado (Adler-Nissen, 1986) y un a de 0,99, calculado en función del $\mathrm{pH}$ y la temperatura de reacción, de acuerdo a las ecuaciones 2 y 3 respectivamente (Forghani et al., 2012).

$\propto=\frac{10^{\mathrm{pH}-\mathrm{pK}}}{\left(1+10^{\mathrm{pH}-\mathrm{pK}}\right)}$

$\mathrm{pK}=7,8+\frac{(298-\mathrm{T})}{298 * \mathrm{~T}} * 2400$

\section{Diseño experimental}

Se plateó un diseño experimental de superficie de respuestas central compuesto de cara centrada. Con los factores $\mathrm{Cg}(1,9-33 \%)(\mathrm{p} / \mathrm{p})$ y $\mathrm{Va}(240-1200 \mathrm{rpm})$, tomando $\mathrm{GH}$ como la variable respuesta. Se desarrollaron 13 experimentos de acuerdo al diseño experimental, según se indica en la Tabla 1. Se empleó el software Design- Expert® 8.0.5 (Stat-Ease, EE.UU.) en la generación y análisis de los datos del diseño. La adecuación del modelo, la significancia estadística de los coeficientes de regresión y la interacción entre las diferentes variables independientes fueron probados mediante el análisis de varianza (ANOVA). La significancia de los coeficientes estimados en el modelo se probó con el estadístico $F$ (valor-P) y un nivel de confianza del $95 \%$.

Tabla 1: Diseño experimental de superficie de respuestas central compuesto de la hidrólisis enzimática de VTR

\begin{tabular}{ccc}
\hline$V a(r p m)$ & $C g(\%)$ & $G H(\%)$ \\
\hline 1200 & 33,0 & 8,39 \\
720 & 33,0 & 6,65 \\
720 & 1,9 & 9,38 \\
1200 & 17,4 & 9,18 \\
720 & 17,4 & 9,62 \\
240 & 33,0 & 4,71 \\
720 & 17,4 & 10,15 \\
720 & 17,4 & 9,67 \\
240 & 1,9 & 6,65 \\
720 & 17,4 & 10,17 \\
720 & 17,4 & 8,50 \\
240 & 17,4 & 5,48 \\
1200 & 1,9 & 9,48 \\
\hline
\end{tabular}


Adicionalmente, se llevó a cabo la optimización del modelo polinomial obtenido, para determinar las condiciones de $\mathrm{Cg}$ y Va que maximizan el $\mathrm{GH}$ en $4 \mathrm{~h}$ de reacción, empleando la técnica de modelos de superficie de respuesta. El ajuste del modelo empírico se verificó a la luz de los resultados experimentales, realizando tres replicas experimentales y comparando estos resultados con los predichos por el modelo polinomial ajustado.

\section{Actividad enzimática}

La actividad catalítica se determinó mediante un análisis estándar usando caseína como sustrato, según la metodología descrita por Cheung et al. (2012). En este análisis, una unidad de actividad es representada por una producción de color equivalente a $1 \mu \mathrm{mol}$ de tirosina por min a $\mathrm{pH} 7,5$ y $37^{\circ} \mathrm{C}$. Para esto, una alícuota de $100 \mu \mathrm{L}$ de enzima fue incubada con $500 \mu \mathrm{L}$ de solución de caseína $0,65 \%$, durante 10 min a $37^{\circ} \mathrm{C}$. La reacción se detuvo adicionando $500 \mu \mathrm{l}$ de solución de ácido tricloro acético $(110 \mathrm{mM})$ y la mezcla se centrifugó, para tomar $200 \mu \mathrm{L}$ del sobrenadante y mezclarlos con $500 \mu \mathrm{L}$ de $\mathrm{Na}_{2} \mathrm{CO}_{3} 0,5 \mathrm{M}$ y $100 \mu \mathrm{L}$ del reactivo de Folinciacalteu. Esta última solución fue incubada a $37^{\circ} \mathrm{C}$ por $30 \mathrm{~min}$ y la absorbancia se leyó en un espectrofotómetro a 660nm (GENESYS 10S UV-Vis, Thermo Scientific ${ }^{\mathrm{TM}}$, EE.UU.). Como patrón se empleó una curva estándar de solución de Tirosina entre 0-200 mg/L.

\section{Efecto de la agitación sobre la actividad de la Alcalasa 2,4L}

Para determinar si la Alcalasa 2,4 L sufre algún tipo de daño permanente, que genere inactivación de la misma por el efecto mecánico que se imprime al sistema asociado a la velocidad de agitación; se prepararon $500 \mathrm{~mL}$ de la enzima en ausencia de sustrato, diluida a una concentración de $0,017 \mathrm{~g} / \mathrm{mL}$ (cantidad mínima de enzima necesaria para evaluar la actividad catalítica), a las mismas condiciones en las que se realizó la reacción de hidrolisis: $\mathrm{pH} 9,5$ y $53^{\circ} \mathrm{C}$. La solución fue sometida a agitación constante de 480, 960 y 1440 rpm durante 4 horas y se tomó muestra cada $40 \mathrm{~min}$, a las cuales se le midió la actividad catalítica residual mediante el método descrito por Cheung et al. (2012). Adicionalmente, para determinar si el efecto que la agitación ejerce es sobre la interacción de la enzima con el sustrato, se realizaron ensayos de actividad catalítica de la Alcalasa 2,4L con el método descrito por Cheung et al. (2012), en un reactor de vidrio de $500 \mathrm{~mL}$ y variando las velocidades de agitación (entre 0 y $1440 \mathrm{rpm}$ ), durante los $10 \mathrm{~min}$ de incubación de la enzima con el sustrato de la prueba de actividad catalítica (caseína).

\section{Determinación del patrón de inhibición de la grasa sobre la Alcalasa 2,4L}

Para investigar el tipo de inhibición que ejerce la grasa presente en las vísceras, sobre la Alcalasa 2,4L, la hidrolisis de VTR fue realizada a $53^{\circ} \mathrm{C}, \mathrm{pH} 9,5$ y agitación constante de $960 \mathrm{rpm}$, usando tres niveles de $\mathrm{Cg}$ : 1,$9 ; 33$ y $56,1 \%(\mathrm{p} / \mathrm{p})$ y diferentes concentraciones iniciales de sustrato (S) para cada $\mathrm{Cg}$. En cada ensayo se determinó la velocidad inicial de reacción, como la pendiente de la porción lineal de la gráfica de concentración de producto $(\mathrm{P})$ en función del tiempo, donde $\mathrm{P}$ es calculada como el número de enlaces peptídicos rotos según la ecuación 4. Las cinéticas de la Alcalasa 2,4L en presencia del inhibidor (grasa) fueron determinadas mediante el análisis de gráficos de Lineweaver-Burk.

$P=\frac{\mathrm{B} \mathrm{N}}{\alpha}$

\section{Análisis estadístico}

Para determinar si existe diferencia estadísticamente significativa entre los valores de actividad enzimática de la Alcalasa 2,4L a los diferentes niveles de agitación, las mediciones se hicieron por triplicado y se utilizó la prueba de la mínima diferencia significativa (LSD), usando el paquete estadístico Statgraphics Centurion (XV) 16.1.15 ((StatPoint, Inc., EE.UU.).

\section{RESULTADOS Y DISCUSIÓN}

Para una mejor presentación y discusión, los resultados encontrados en este estudio se muestran y analizan en varias sub-secciones: (i) análisis químico proximal de las vísceras; (ii) el efecto de $\mathrm{Cg}$ y Va sobre el proceso de hidrólisis; (iii) la optimización del modelo; (iv) inactivación de la Alcalasa 2,4l por efecto de la agitación; y (v) el tipo de inhibición de la grasa sobre la Alcalasa 2,4l

\section{Análisis químico proximal de las vísceras}

En la tabla 2 se muestra la composición química proximal de las vísceras enteras y desengrasadas. Otros autores han señalado resultados similares en cuanto a la composición proximal de vísceras enteras de otras especies (Bhaskar y Mahendrakar, 2008; Šližyte et al., 2005), sin embargo de las vísceras desengrasadas no han sido ampliamente reportadas. 
Tabla 2: Composición proximal de las vísceras enteras y desengrasadas

\begin{tabular}{ccc}
\hline Composición $g / 100 g$ & Vísceras enteras & Vísceras desengrasadas \\
\hline Humedad & 62,00 & 83,21 \\
Lípidos & 26,08 & 1,88 \\
Proteína & 8,48 & 10,04 \\
Cenizas & 1,19 & 1,71 \\
\hline
\end{tabular}

\section{Efecto de Cg y Va sobre el proceso de hidrólisis}

En la tabla 1 se muestran las 13 corridas del diseño experimental en forma aleatoria y los valores de la variable respuesta obtenida en cada corrida. Mientras que en la tabla 3 aparece el ANOVA del diseño experimental, el cual contiene la significancia estadística del modelo, de cada factor o interacción (valor-P), el $R^{2}, R^{2}$-Ajustado y la carencia de ajuste.

Tabla 3: Análisis de varianza (Valor- P) del diseño factorial

\begin{tabular}{ll}
\hline Fuente $\left(\mathrm{X}_{\mathrm{i}}\right)$ & Valor- $\mathrm{P}$ \\
\hline Modelo & 0,0006 \\
$\mathrm{Va}$ & 0,0008 \\
$\mathrm{Cg}$ & 0,0203 \\
$\mathrm{Va}^{2}$ & 0,0032 \\
Carencia de ajuste & 0,2732 \\
\hline $\mathrm{R}^{2}$ & 0,8437 \\
$\mathrm{R}^{2}$ Ajustado & 0,7917 \\
\hline
\end{tabular}

El ANOVA indica un modelo altamente significativo, donde Va es el factor con mayor influencia sobre GH, con efecto en su término lineal y cuadrático. Mientras que $\mathrm{Cg}$ solo tiene efecto en su término lineal. Así mismo, el ANOVA entrega un polinomio de segundo orden (Ecuación 5), el cual describe la influencia de las variables sobre el GH de proteínas de VTR.

$G H=3,528+(1,811 \times V a)-(0,062 \times C g)-\left(0,115 \times V a^{2}\right)$

En la Figura 1 se muestra el comportamiento gráfico de la respuesta $(\mathrm{GH})$ en función a los dos factores. En concordancia con el modelo ajustado, se puede ver un efecto más marcado por Va que por $\mathrm{Cg}$. Se puede notar también, que la concentración de grasa tiene un efecto negativo sobre el GH de la reacción, lo que sugiere que la grasa genera interferencias en la hidrolisis de proteínas. Dicho fenómeno han sido poco estudiado, pero algunos autores lo atribuyen a complejos proteína-lípido formados, los cuales son más resistentes a la acción catalítica de las proteasas (Šližyte et al., 2005).

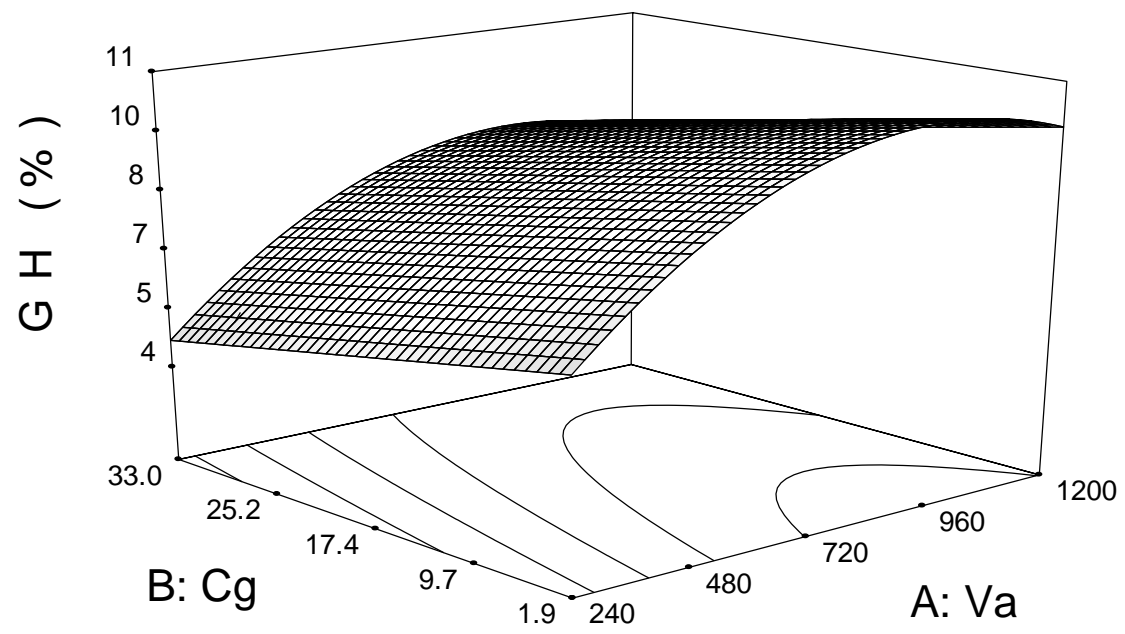

Fig. 1: Gráfico de contornos para el efecto de Va y $\mathrm{Cg}$ sobre el GH de la reacción. 
Por otro lado, Va en su término lineal tiene un efecto positivo sobre el $\mathrm{GH}$, pero en su término cuadrático tiene un efecto negativo. Esto indica que aumentar Va favorece la reacción, posiblemente porque ayuda a mantener una mayor homogeneidad en la muestra, sin embargo por encima de un cierto valor de Va, este factor empieza a ejercer un efecto negativo sobre el $\mathrm{GH}$, por lo que se señala un cambio en la pendiente de la gráfica. Este fenómeno podría deberse a que un aumento excesivo en la velocidad de agitación ocasiona ya sea un cambio conformacional de la Alcalasa 2,4L, que dificulta la interacción enzima-sustrato, o conlleva a un proceso de inactivación-agregación de la enzima. Este último fenómeno ha sido reportado por algunos autores, quienes han estudiado la influencia de parámetros hidrodinámicos como la agitación mecánica y han demostrado un efecto de inactivación enzimática debido al incremento en la velocidad de agitación (Caussette et al., 1997; Colombié et al., 2001; Colombié et al., 2000).

\section{Optimización del modelo}

El modelo de la ecuación 5, fue optimizado para predecir el valor de los factores que maximice el GH, así mismo se desarrollaron ensayos experimentales a las condiciones óptimas para evaluar la validez de este modelo. Estos resultados se presentan en la tabla 4, en los que se incluye el error relativo existente entre los valores predichos y experimentales. Este último parámetro señala la capacidad del modelo para predecir el comportamiento del $\mathrm{GH}$ en función de $\mathrm{Va}$ y $\mathrm{Cg}$.

Tabla 4: Máximos locales predichos en la optimización de la hidrólisis enzimática de VTR

\begin{tabular}{cc|ccc}
\hline Factor & Valor óptimo & Tiempo predicho & Tiempo experimental & Error relativo \\
\hline $\mathrm{Va}(\mathrm{rpm})$ & 982 & 10,00 & $9,51 \pm 0,02$ & $4,9 \%$ \\
$\mathrm{Cg}(\% \mathrm{p} / \mathrm{p})$ & 2,0 & & & \\
\hline
\end{tabular}

\section{Inactivación de la Alcalasa 2,4L por efecto de la agitación}

En la figura 2 se presenta la actividad de la Alcalasa 2,4L en solución acuosa, en ausencia de sustrato, pH 9,5 y $53{ }^{\circ} \mathrm{C}$, para diferentes velocidades de agitación. Se puede observar que la actividad catalítica de la enzima desciende con el tiempo, sin embargo, entre las diferentes velocidades de agitación no presentan diferencias estadísticamente significativas en los primeros $200 \mathrm{~min}$ de reacción. Lo que sugiere que dicha inactivación no puede atribuirse a daños mecánicos en la enzima, ocasionados por la agitación, sino que podrían deberse a otros factores como la temperatura o el pH (Lassé et al., 2015; Valencia et al., 2014). No obstante en la última medición, la actividad enzimática de la Alcalasa 2,4L sometida a la mayor velocidad de agitación (1440 rpm), es menor a la encontrada para las otras dos velocidades; indicando que largos periodos de tiempo bajo altas velocidades de agitación, podrían ocasionar disminución en la eficiencia de la enzima, inducida por interfaces físicas y catalizada por el incremento de superficies hidrofóbicas de las enzimas inactivadas, tal como lo propuso Colombié et al. (2001).

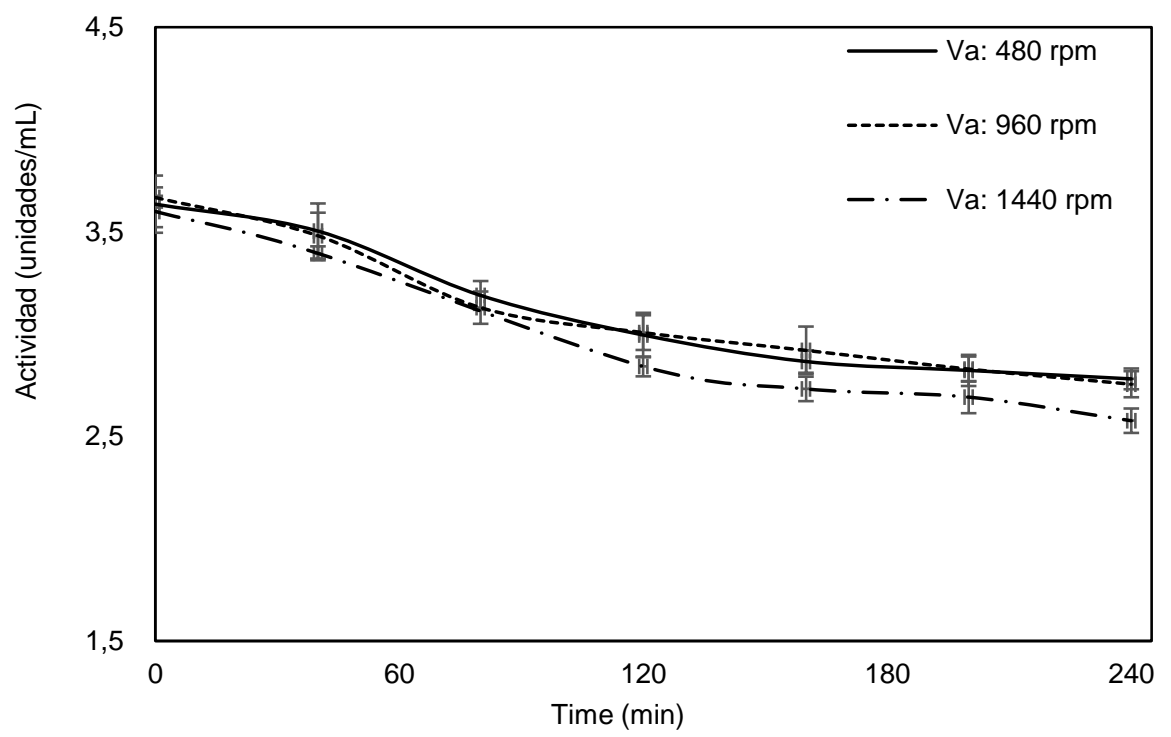

Fig. 2: Cinética de inactivación de la Alcalasa 2,4L bajo diferentes niveles de agitación 
Teniendo en cuenta que el efecto que presentó la Va en el diseño experimental, no puede ser explicado por una inactivación o agregación enzimática, se realizaron ensayos para evaluar si el aumento de Va podía disminuir la eficiencia catalítica de la enzima, posiblemente por dificultar la interacción enzima-sustrato. En la Figura 3 se muestra como incrementos en Va favorece la actividad catalítica de la enzima, pero valores por encima de $960 \mathrm{rpm}$ ocasionan una disminución en la eficiencia de la Alcalasa, como ya se había observado a partir del diseño experimental. Este comportamiento se puede deber a que inicialmente el incremento de Va proporciona mayor homogeneidad del medio, favoreciendo el encuentro de la enzima con el sustrato, pero por encima de cierto límite, los incremento de Va puede provocar alteraciones negativas en el desempeño de la enzima.

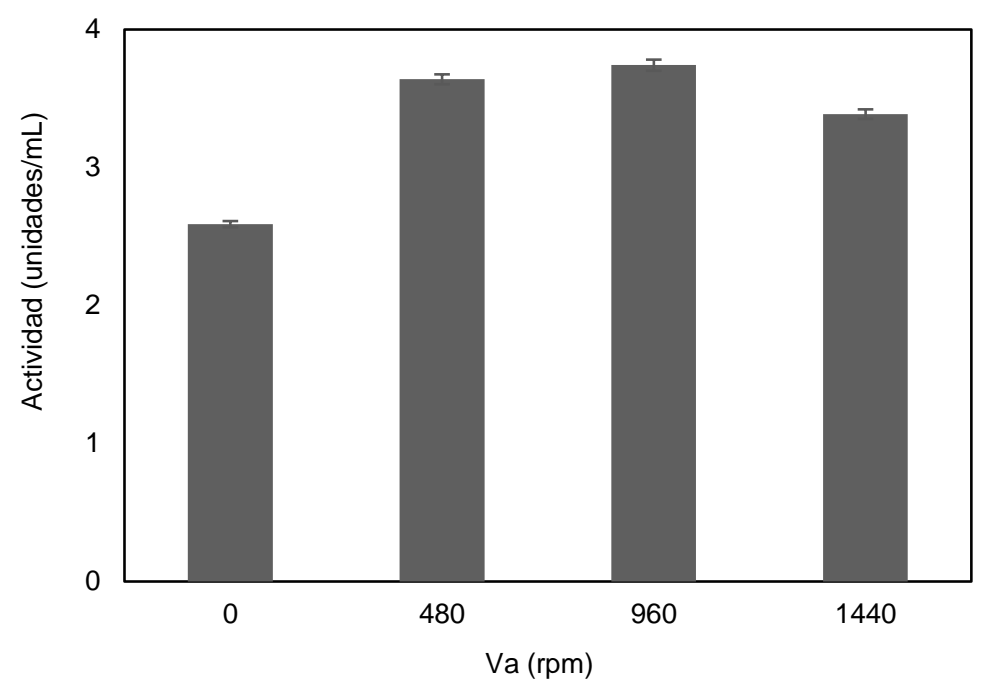

Fig. 3: Actividad catalítica de la alcalasa 2,4 L a diferentes velocidades de agitación

Tipo de inhibición de la grasa sobre la Alcalasa 2,4L

Con el diseño experimental se pudo determinar que la grasa de las vísceras ejerce un efecto negativo sobre el proceso de hidrolisis. Para determinar si se trata de un efecto inhibitorio sobre la Alcalasa 2,4L y establecer cuál es el tipo de inhibición que se ejerce, se usaron gráficos de Lineweaver-Burk (Figura 4), con diferentes niveles de grasa (inhibidor). Se encontró que la grasa, tienen un patrón inhibitorio competitivo sobre la Alcalasa 2,4 L, y que aumentos en la concentración de grasa por encima de 1,9\% no muestran un aumento representativo en la magnitud de la inhibición. El tipo de inhibición ejercido por la grasa sobre la Alcalasa 2,4L, podría explicarse dado que la subtilisina, que es componente mayoritario de la Alcalasa 2,4L, es una serin proteasa que cataliza no solo la hidrolisis de amidas, sino también de esteres (Wong, 1995); teniendo en cuanta el alto número de enlaces éster en la grasa (Belitz et al., 2009), es de esperarse que está constituya un inhibidor competitivo por la alta reactividad con el sitio activo de la Subtilisina.

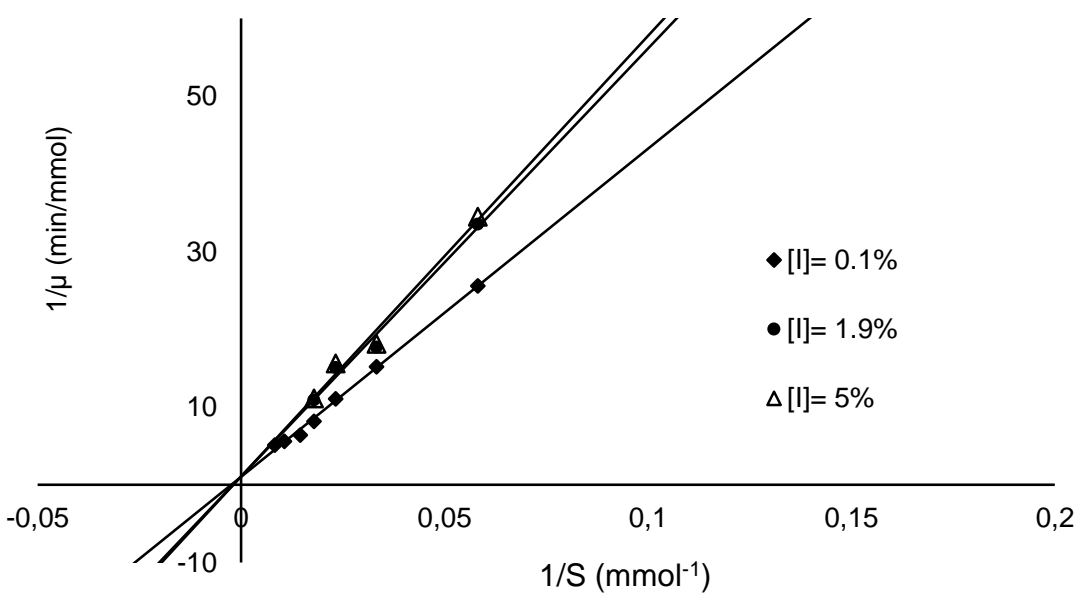

Fig. 4: Gráfico de Lineweaver-Burk para la velocidad de reacción de la Alcalasa 2,4L en presencia de grasa 
Estos resultados contradicen algunos reportes de literatura en los que las muestras desengrasadas presentaron un menor $\mathrm{GH}$, lo cual se atribuyó a la desnaturalización de la proteína en los procesos de desengrasado (Hoyle y Merritt, 1994; Klompong et al., 2007). Sin embargo, en el presente estudio todas las muestras se sometieron al mismo pretratamiento, independientemente del nivel de grasa que se fuera a tener en la muestra. Por tal razón, la diferencia en los resultaos se debe únicamente a la diferencia en los niveles de grasa presentes.

\section{CONCLUSIONES}

Se ajustó un modelo polinomial de segundo orden que describe adecuadamente la influencia de $\mathrm{Va}$ y $\mathrm{Cg}$ sobre el GH de la reacción de hidrólisis enzimática de las VTR, y se determinó que las condiciones que maximizan el GH de la reacción del sistema VTR-Alcalasa 2,4L, en la región experimental son: Va de 982 rpm y $\mathrm{Cg}$ de $2,0 \%$, con las que es posible obtener hidrolizados con $\mathrm{GH}$ de $9,5 \%$.

Se logró además determinar que la grasa de las vísceras de tilapia roja (Orechromis $s p$.), ejerce una inhibición competitiva sobre la Alcalasa 2,4L y que la velocidad de agitación del sistema de reacción, aunque no logra inactivar la enzima en las primeras 4 horas, si tienen un efecto negativo sobre su actividad catalítica cuando se manejan niveles superiores a $960 \mathrm{rpm}$.

\section{AGRADECIMIENTOS}

Los autores del presente trabajo dan las gracias a la Gobernación de Antioquia, al Sistema General de Regalías de Colombia y a la estrategia de sostenibilidad 2014-2015 del Comité para el Desarrollo de la Investigación en la Universidad de Antioquia (CODI), por el apoyo financiero entregado.

\section{REFERENCIAS}

Adler-Nissen, J., Enzymic hydrolysis of food proteins, 116-124, Elsevier, Londres, Inglaterra (1986)

AOAC. Official Methods of Analysis (sixteenth), Washington DC, United States of America (2005)

Baez, A.J., Ospina, N. y Zapata, J.E., Efecto de Temperatura, pH, Concentración de Sustrato y Tipo de Enzima en la Hidrólisis Enzimática de Vísceras de Tilapia Roja (Oreochromis Spp.), http://doi.org/10.4067/S0718-07642016000600007, Información Tecnológica, (en línea), 27(6), 63-76 (2016)

Belitz, H.D., W. Grosch y P. Schieberle, Food Chemistry, Print ISBN: 978-3-540-69933-0, Online ISBN: 9783-540-69934-7, DOI: 10.1007/978-3-540-69934-7, Springer Berlin Heidelberg (2009)

Bhaskar, N. y N.S., Mahendrakar, Protein hydrolysate from visceral waste proteins of Catla (Catla catla): Optimization of hydrolysis conditions for a commercial neutral protease, http://doi.org/10.1016/j.biortech.2007.09.006, Bioresource Technology, (en línea), 99(10), 4105-4111 (2008)

Caussette, M., H. Planche, S. Delepine, P. Monsan, A. Gaunand y B. Lindet, The self-catalytic enzyme inactivation induced by solvent stirring: a new example of protein conformational change induction, http://doi.org/10.1093/protein/10.10.1235, Protein Engineering, (en línea), 10(10), 1235-40 (1997)

Chalamaiah, M., B. Dinesh, R. Hemalatha y T. Jyothirmayi, Fish protein hydrolysates: Proximate composition, amino acid composition, antioxidant activities and applications: A review, http://doi.org/10.1016/j.foodchem.2012.06.100, Food Chemistry, (en línea), 135(4), 3020-3038 (2012)

Cheung, I. W. Y., L. K. Y. Cheung, N. Y. Tan y E. C. Y. Li-Chan, The role of molecular size in antioxidant activity of peptide fractions from Pacific hake (Merluccius productus) hydrolysates, http://doi.org/10.1016/j.foodchem.2012.02.215, Food Chemistry, (en línea), 134(3), 1297-1306 (2012)

Colombié, S., A. Gaunand y B. Lindet, Lysozyme inactivation under mechanical stirring: Effect of physical and molecular interfaces, http://doi.org/10.1016/S0141-0229(01)00340-4, Enzyme and Microbial Technology, (en línea), 28(9-10), 820-826 (2001)

Colombié, S., A. Gaunand, M. Rinaudo y B. Lindet, Irreversible lysozyme inactivation and aggregation induced by stirring: kinetic study and aggregates characterisation, http://doi.org/10.1023/A:1005655005780, Biotechnology Letters, (en línea), 22(4), 277-283 (2000) 
Copeland, R. A., Enzymes: A Practical Introduction to Structure, Mechanism, and Data Analysis, 2a Ed., Wiley-VCH, New York (2000)

England, E.M., S.K. Matarneh, T.L. Scheffler, C. Wachet y D.E. Gerrard, pH inactivation of phosphofructokinase arrests postmortem glycolysis, http://doi.org/10.1016/j.meatsci.2014.07.019, Meat Science, (en línea), 98(4), 850-857 (2014)

Forghani, B., A. Ebrahimpour, J. Bakar, A. A. Hamid, Z. Hassan, y N. Saari, Enzyme Hydrolysates from Stichopus horrens as a New Source for Angiotensin-Converting Enzyme Inhibitory Peptides, http://dx.doi.org/10.1155/2012/236384, Evidence-based Complementary and Alternative Medicine, (en línea), 2012, 1-9 (2012)

García, C. O., R. Pacheco, S. Valdez, E. Márquez, M. E. Lugo, y J. M. Ezquerra, Impact of stickwater produced by the fishery industry: treatment and uses, CyTA - J. Food, 7 (1), 67-77 (2009)

Gómez, L. J., O. A. Figueroa, y J. E. Zapata, Actividad antioxidante de hidrolizados enzimáticos de plasma bovino obtenidos por efecto de alcalasa ${ }^{\circledR} 2.4$ L, http://dx.doi.org/10.4067/S0718-07642013000100005, Información Tecnológica, (en línea), 24(1), 33-42 (2013)

Gómez, L. J. y J. E. Zapata, Effects of Hydrolysis and Digestion in Vitro on the Activity of Bovine Plasma Hydrolysates as Inhibitors of the Angiotensin I Converting Enzyme. Brazilian Archives of Biology and Technologyiology, ISSN: 1678-4324 (en línea: https://goo.gl/UJwnym), 57(3), 386-393 (2014)

Gómez, L.J. y J. E. Zapata, Obtaining of antioxidant peptide from bovine plasma Hydrolysates and effect of the degree of hydrolysis on Antioxidant capacity, http://www.redalyc.org/pdf/620/62045307011.pdf, Revista Mexicana de Ingeniería Química, ISSN: 1665-2738 (en línea), 15(1), 101-109 (2016)

Guadix, A., E. Guadix, M. Páez, P. González y F. Camacho, Procesos tecnológicos y métodos de control en la hidrólisis de proteínas, http://farmacia.ugr.es/ars/pdf/183.pdf, Ars Pharmaceutica, 41(1), 79-89 (2000)

Hoyle, N. y J. Merritt, Quality of Fish Protein Hydrolysates from Herring (Clupea harengus), http://doi.org/10.1111/j.1365-2621.1994.tb06901.x, Journal of Food Science, (en línea), 59(1), 76-79 (1994)

Je, J.Y., S.Y. Park, J.Y. Hwang y C.B. Ahn, Amino acid composition and in vitro antioxidant and cytoprotective activity of abalone viscera hydrolysate, http://doi.org/10.1016/j.jff.2015.04.023, Journal of Functional Foods, (en línea), 16, 94-103 (2015)

Klompong, V., S. Benjakul, D. Kantachote y F. Shahidi, Antioxidative activity and functional properties of protein hydrolysate of yellow stripe trevally (Selaroides leptolepis) as influenced by the degree of hydrolysis and enzyme type, http://doi.org/10.1016/j.foodchem.2006.07.016, Food Chemistry, (en línea), 102(4), 13171327 (2007)

Lassé, M., S. Deb-Choudhury, S. Haines, N. Larsen, J. A. Gerrard y J. M. Dyer, The impact of pH, salt concentration and heat on digestibility and amino acid modification in egg white protein, http://doi.org/10.1016/j.jfca.2014.08.007, Journal of Food Composition and Analysis, (en línea), 38, 42$48(2015)$

Martínez Alvarez, O., S. Chamorro y A. Brenes, Protein hydrolysates from animal processing byproducts as a source of bioactive molecules with interest in animal feeding: A review, http://doi.org/10.1016/j.foodres.2015.04.005, Food Research International, (en línea), 73(1069), 204$212(2015)$

Robert, M., C. Zatylny-gaudin, V. Fournier, E. Corre, G. Le, B. Bernay y J. Henry, Molecular characterization of peptide fractions of a Tilapia (Oreochromis niloticus ) by-product hydrolysate and in vitro evaluation of antibacterial activity, http://dx.doi.org/10.1016/j.procbio.2014.12.022, Process Biochemistry, (en línea), 50, 487-492 (2015)

Saidi, S., Deratani, A., Belleville, M.P. y Amar, R.B., Production and fractionation of tuna by-product protein hydrolysate by ultrafiltration and nanofiltration: Impact on interesting peptides fractions and nutritional properties, doi:10.1016/j.foodres.2014.04.026, Food Research International, (en línea), 65 (Part C) 453-461 (2014) 
Šližyte, R., E. Daukšas, E. Falch, I. Storrø y T. Rustad, Characteristics of protein fractions generated from hydrolysed cod (Gadus morhua) by-products, http://doi.org/10.1016/j.procbio.2004.07.016, Process Biochemistry, (en línea), 40(6), 2021-2033 (2005)

Valencia, P., M. Pinto, y S. Almonacid, Identification of the key mechanisms involved in the hydrolysis of fish protein by Alcalase, http://doi.org/10.1016/j.foodchem.2015.11.024, Process Biochem., (en línea), 49(2), 258-264 (2014)

Verhaeghe, T., G. Vlaemynck, J. De Block, S. Van Weyenberg y M. Hendrickx, Thermal inactivation kinetics of proteases and polyphenoloxidase in brown shrimp (Crangon crangon), Food Chemistry, (en línea), 197, 641-647 (2016)

Wong, D. W. S., Food Enzymes: Structure and Mechanism, $1^{\text {a }}$ edición, Dordrech: Springer Science \& Business Media (1995)

Zheng, L., Y. Zhao, C. Xiao, D. Sun-Waterhouse, M. Zhao y G. Su, Mechanism of the discrepancy in the enzymatic hydrolysis efficiency between defatted peanut flour and peanut protein isolate by Flavorzyme, http://doi.org/10.1016/j.foodchem.2014.07.037, Food Chemistry, (en línea), 168, 100-106 (2015)

Zhu, K., X. Wang y X. Guo, Isolation and characterization of zinc-chelating peptides from wheat germ protein hydrolysates, http://doi.org/http://dx.doi.org/10.1016/j.jff.2014.10.030, Journal of Functional Foods, (en línea) 12, 23-32 (2015) 